\section{BRAZIULIAN JOURNAL}

OF MEDICAL AND BIOLOGICAL RLSH.ARCH

www.bjournal.com.br
ISSN 0100-879X

Volume 43 (01) 1-123 January 2010

BIOMEDICAL SCIENCES

AND

CLINICAL INVESTIGATION

Braz J Med Biol Res, J anuary 2010, Volume 43(1) 100-106

L-histidine provokes a state-dependent memory retrieval deficit in mice re-exposed to the elevated plus-maze

K.R. Serafim, M. Kishi, A. Canto-de-Souza and R. Mattioli

The Brazilian Journal of Medical and Biological Research is partially financed by
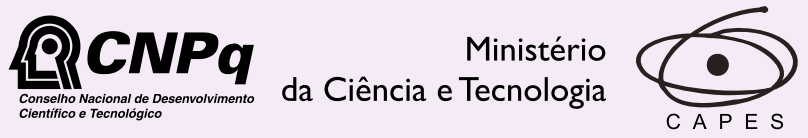

Ministério da Educação

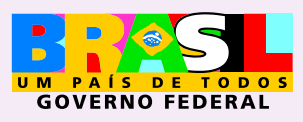

Institutional Sponsors 


\title{
L-histidine provokes a state-dependent memory retrieval deficit in mice re-exposed to the elevated plus-maze
}

\author{
K.R. Serafim ${ }^{1}$, M. Kishi ${ }^{1}$, A. Canto-de-Souza ${ }^{2}$ and R. Mattioli ${ }^{1}$ \\ ${ }^{1}$ Laboratório de Neurociências, ${ }^{2}$ Laboratório de Psicologia da Aprendizagem, \\ Universidade Federal de São Carlos, São Carlos, SP, Brasil
}

\begin{abstract}
The effects of L-histidine (LH) on anxiety and memory retrieval were investigated in adult male Swiss Albino mice (weight 30 $35 \mathrm{~g}$ ) using the elevated plus-maze. The test was performed on two consecutive days: trial 1 (T1) and trial 2 (T2). In T1, mice received an intraperitoneal injection of saline (SAL) or LH before the test and were then injected again and retested $24 \mathrm{~h}$ later. $\mathrm{LH}$ had no effect on anxiety at the dose of $200 \mathrm{mg} / \mathrm{kg}$ since there was no difference between the SAL-SAL and LH-LH groups at T1 regarding open-arm entries (OAE) and open-arm time (OAT) (mean \pm SEM; OAE: $4.0 \pm 0.71,4.80 \pm 1.05$; OAT: 40.55 \pm 9.90, $51.55 \pm 12.10$, respectively; $P>0.05$, Kruskal-Wallis test), or at the dose of $500 \mathrm{mg} / \mathrm{kg}$ (OAE: $5.27 \pm 0.73,4.87 \pm 0.66$; OAT: $63.93 \pm 11.72,63.58 \pm 10.22 ; \mathrm{P}>0.05$, Fisher LSD test). At T2, LH-LH animals did not reduce open-arm activity (OAE and OAT) at the dose of $200 \mathrm{mg} / \mathrm{kg}(\mathrm{T} 1: 4.87 \pm 0.66, \mathrm{~T} 2: 5.47 \pm 1.05 ; \mathrm{T} 1: 63.58 \pm 10.22, \mathrm{~T} 2: 49.01 \pm 8.43$ for OAE and OAT, respectively; $\mathrm{P}>0.05$, Wilcoxon test) or at the dose of $500 \mathrm{mg} / \mathrm{kg}(\mathrm{T} 1: 4.80 \pm 1.60$, T2: $4.70 \pm 1.04 ; \mathrm{T} 1: 51.55 \pm 12.10$, T2: 43.88 \pm 10.64 for OAE and OAT, respectively; $\mathrm{P}>0.05$, Fisher LSD test), showing an inability to evoke memory $24 \mathrm{~h}$ later. These data suggest that LH does not act on anxiety but does induce a state-dependent memory retrieval deficit in mice.
\end{abstract}

Key words: L-histidine; Anxiety; Emotional memory; Elevated plus-maze; Memory retrieval deficit

\section{Introduction}

In the mammalian brain, the histaminergic neuron cell bodies are found in the tuberomammillary nucleus of the posterior hypothalamus and these neurons have widespread projections to all major brain areas (1). The action of histamine $(\mathrm{HA})$ is mediated by at least four types of receptors denoted $\mathrm{H}_{1}, \mathrm{H}_{2}, \mathrm{H}_{3}$, and $\mathrm{H}_{4}(2)$. Studies have indicated the importance of the neural histaminergic system (NHS) in animal behaviors, primarily anxiety (3), learning and memory $(4,5)$. Recent reports have also provided some insight about the involvement of the NHS in Alzheimer's disease $(6,7)$ and state-dependent memory (8).

The reports on the actual role of this neurotransmitter during the acquisition and storage of information and memory retrieval are highly contradictory (9). Some studies describe the inhibitory effects of HA on learning and memory processes $(10,11)$, while others have provided evidence that $\mathrm{HA}$ plays a role in reinforcement and mnemonic processes $(12,13)$. A relationship between the NHS and anxiety has been suggested in studies of the behavior of fish $(3,14)$ and rodents $(15,16)$. We have reported that chlorpheniramine, a histaminergic $\mathrm{H}_{1}$ receptor antagonist, modulates some components of emotional learning in fish (3). Kamei and Tasaka (17) showed that the intracerebroventricular (icv) injection of HA and L-histidine (LH) prior to the test caused a significant reduction of the latency response in old rats in an active avoidance response test, therefore facilitating the memory processes. de Almeida and Izquierdo (18) demonstrated that the immediate post-training icv administration of $\mathrm{HA}$ facilitated performance in a retention test of step-down inhibitory avoidance behavior measured 24 $\mathrm{h}$ later, in rats.

Some investigators also studied the effect of the histaminergic system on anxiety and emotional memory using the elevated plus-maze (EPM) test $(19,20)$. This test has shown good sensitivity to both anxiogenic and anxiolytic drugs $(21,22)$ and the EPM has also been used to understand the biological basis of emotional memory related to learning and memory. Another characteristic of this test is

Correspondence: R. Mattioli, Departamento de Fisioterapia, Universidade Federal de São Carlos, Rodovia Washington Luiz, 235, 13565-905 São Carlos, SP, Brasil. Fax: +55-16-3361-2081. E-mail: mattioli@ufscar.br

Received June 10, 2009. Accepted November 23, 2009. Available online December 7, 2009. Published January 11, 2010. 
the use of the test-retest protocol (23). Albeit some studies have reported the involvement of the NHS in emotional memory, there is not much information about the effects of HA on the acquisition of emotion-related learning in rodents. Thus, the objective of the present study was to determine the effects of the LH on anxiety and retrieval of emotional memory in mice using the EPM retest.

\section{Material and Methods}

\section{Subjects}

Adult male Swiss Albino mice supplied by the Animal Facility of the Federal University of São Carlos, SP, Brazil, weighing $30-35 \mathrm{~g}$ at the time of testing were housed in groups of 10 per cage $(41 \times 34 \times 16 \mathrm{~cm})$ in a temperatureand light cycle-controlled environment $\left(24 \pm 1^{\circ} \mathrm{C}\right)$. All testing was conducted during the light phase of the cycle between 9:00 am and 4:00 pm. Food and water were freely available except during the brief test periods. The mice were experimentally naive. All procedures were approved by the Ethics Committee on Animal Experimentation of the Federal University of São Carlos (\#028/2007). All efforts were made to minimize animal suffering.

\section{Drugs}

L-histidine hydrochloride (a precursor of histamine; RBI, USA) was dissolved in sterile $0.9 \%$ saline (SAL). The injections were administered intraperitoneally (ip) at a volume of 2 and $5 \mathrm{~mL} / \mathrm{kg}$ body weight and the final dose was 200 , 500 and $1000 \mathrm{mg} / \mathrm{kg}$. The different injection volumes used ( 2 and $5 \mathrm{~mL} / \mathrm{kg}$ ) were necessary because of the relatively limited solubility of LH (1000 mg/kg). The doses used were based on previous studies (24) as well as on a pilot study conducted by us.

Saline was used as control. Both drugs and saline were placed in coded Eppendorf tubes under refrigeration. This coding was unknown to the experimenter at the time of the tests and behavioral analysis.

\section{Elevated plus-maze and general procedure}

The apparatus used for the test procedures was the same as the EPMs developed and validated for rats (22) and mice (25). It was constructed from wood and had transparent glass walls for the enclosed arms. The maze consists of four arms, two open $(30 \times 5 \times 0.25 \mathrm{~cm})$ and two enclosed arms $(30 \times 5 \times 15 \mathrm{~cm})$, extending from a common central platform $(5 \times 5 \mathrm{~cm})$ and was elevated to a height of $38.5 \mathrm{~cm}$. All testing was conducted under moderate illumination $(77 \mathrm{~lx})$ measured on the central platform of the EPM during the light phase of the cycle.

To facilitate adaptation, the animals were transported to a dimly illuminated laboratory on the test day and left undisturbed for at least $1 \mathrm{~h}$ prior to testing. The test was performed on 2 consecutive days: trial 1 (T1) and trial 2 (T2). In T1, mice received an ip injection of SAL or LH 40 min before the test. Twenty-four hours later (i.e., T2) the mice were injected again with SAL or LH under the same experimental conditions.

On both test days, the test session was started by placing the subject on the central platform of the maze, facing an open arm and 5 min of free exploration was allowed. Between animals, the maze was thoroughly cleaned with $20 \%$ alcohol. The behavior of the animals was videorecorded by a camera positioned above and at $50^{\circ}$ to the maze, to permit the discrimination and documentation of all behaviors and the video signal was also relayed to a monitor for real-time observation in another room.

\section{Pharmacological treatment}

The animals received an ip injection of SAL or LH 40 min before T1 and T2 (24 h later). For each LH dose administered ( $\mathrm{LH}_{200} \mathrm{mg} / \mathrm{kg}, \mathrm{LH}_{500} \mathrm{mg} / \mathrm{kg}$ and $\mathrm{LH}_{1000 \mathrm{mg} / \mathrm{kg}}$ ), the animals were randomly assigned to four groups based on drug treatment: SAL-SAL, SAL-LH, LH-SAL, and LH-LH (see Table 1).

\section{Behavioral analysis}

Videotapes were scored in a blind fashion by a trained observer using the ethological analysis software package X-Plot-Rat (26). The conventional categories and ethological measures were defined according to previous studies $(25,27)$. Behavioral measures were the frequency of openand enclosed-arm entries (OAE and EAE) defined as all four paws placed inside an arm, total arm entries, and total time spent in the open and enclosed arms and in the central area (TE, OAT, EAT, CT). These data were used to calculate the

Table 1. Experimental protocol.

\begin{tabular}{|c|c|c|c|}
\hline \multirow{2}{*}{$\begin{array}{l}\text { Pharmacological treatment (ip injection) } \\
\text { before T1 and T2 } \\
\mathrm{LH}_{200} \mathrm{mg} / \mathrm{kg}\end{array}$} & \multicolumn{3}{|c|}{ Experimental groups } \\
\hline & SAL-SAL $(N=10) \quad$ SAL-LH $(N=10)$ & LH-SAL $(\mathrm{N}=10)$ & LH-LH $(\mathrm{N}=10)$ \\
\hline $\mathrm{LH}_{500 \mathrm{mg} / \mathrm{kg}}$ & SAL-SAL $(N=11) \quad$ SAL-LH $(N=10)$ & LH-SAL $(N=13)$ & LH-LH $(\mathrm{N}=15)$ \\
\hline $\mathrm{LH}_{1000} \mathrm{mg} / \mathrm{kg}$ & SAL-SAL $(N=11) \quad$ SAL-LH $(N=11)$ & LH-SAL $(N=13)$ & LH-LH $(\mathrm{N}=11)$ \\
\hline
\end{tabular}

Mice received intraperitoneal $(i p)$ injection of saline $(\mathrm{SAL})$ or L-histidine $(\mathrm{LH})$ at the indicated doses on consecutive days and were submitted to an elevated plus-maze test $40 \mathrm{~min}$ after each drug administration. $\mathrm{T} 1=$ trial $1 ; \mathrm{T} 2=$ trial 2. 
percent of OAE \{\%OAE; [(open entries / open + enclosed entries $) \times 100]\}$ and percent of OAT \{\%OAT; [(open time / 300) $x 100]\}$. The ethological measures consisted of the number of stretched-attend postures (SAP; exploratory posture in which the body stretches forward and then retracts to its original position without any forward locomotion), as well as total duration scores in seconds for immobility (complete arrest of movement except for those necessary for respiration). The conventional measure of anxiety consisted of entries and time spent in the open arms on T1 (27). In the EPM, emotional memory can be evaluated by the T1 and T2 paradigms $(28,29)$. Results obtained by Bertoglio and Carobrez (30) showed the presence of progressive avoidance of the open arms, starting at about the 3rd min of T1, which is present during the 1st min in T2. Thus, the EPM allows the evaluation of emotional memory through the T1/T2 paradigm. The decreased open-arm activity (entries and time spent in open arms) in T2 was defined as learning and memory index. Total enclosed arm entries and total arm entries were measured as a relative pure index of locomotor activity (31). With regard to the ethological behavior, SAP was considered to be a primary index of risk assessment (32).

\section{Statistical analysis}

All results were initially submitted to the Levene test for homogeneity of variance. Because data $(200 \mathrm{mg} / \mathrm{kg} \mathrm{LH})$ were not homogeneously distributed, a nonparametric test was applied. The difference between groups was analyzed by the Kruskal-Wallis test. The difference between T1 (exposure) and T2 (retest) was analyzed by the Wilcoxon signed rank test. Data for the LH dose of $500 \mathrm{mg} / \mathrm{kg}$ were analyzed by two-way independent analysis of variance (ANOVA; factor 1: treatment, factor 2: test day). A significant $F$ test was followed by the Fisher LSD test (protected $t$-tests). Finally, data for the LH dose of $1000 \mathrm{mg} / \mathrm{kg}$ were analyzed by the
Student $t$-test and the Mann-Whitney U-test. The level of statistical significance adopted was $P<0.05$. All calculations were performed with the GB-STAT program.

\section{Results}

Figure 1A,B shows that LH (200 mg/kg) treatment had no significant effects on T1 among the SAL-SAL, SAL-LH, LH-SAL, and LH-LH groups for OAE (P = 0.153, KruskalWallis test) and OAT ( $P=0.082$, Kruskal-Wallis test). Table 2 also shows, as determined by the Kruskal-Wallis test, that there were no differences in EAE $(P=0.643)$, EAT $(P=0.279)$, CT $(P=0.104), \% O A E(P=0.123), \% O A T$ $(P=0.082$,$) , indicating that \mathrm{LH}(200 \mathrm{mg} / \mathrm{kg})$ did not act on anxiety (see Table 2).

Figure $1 \mathrm{~A}, \mathrm{~B}$ shows that, as determined by the Wilcoxon test, an ip injection of LH $(200 \mathrm{mg} / \mathrm{kg})$ before T1 and T2 provoked a significant decrease of OAE in T2 for the SALSAL $(P=0.017)$, SAL-LH $(P=0.0002)$ and LH-SAL $(P=$ $0.007)$ groups but not for the LH-LH group $(P=0.799)$. There was a decrease in OAT for the SAL-SAL $(P=0.016)$ and SAL-LH $(P=0.028)$ groups but not for the LH-SAL ( $P$ $=0.345)$ or $\mathrm{LH}-\mathrm{LH}(\mathrm{P}=0.374)$, indicating an inability to evoke memory for the LH-LH group $24 \mathrm{~h}$ later. In addition, the Wilcoxon test showed that the LH-SAL group did not present a reduction of CT in T2 $(P=0.092)$ and that there was a decrease in \%OAE for SAL-SAL $(P=0.016)$ and a decrease in \%OAT for SAL-SAL $(P=0.016)$ and SAL-LH $(P=0.028)$. All experimental groups showed an increase in EAT $(P<0.05)$ in T2 (Table 2).

Repeated measure ANOVA did not reveal significant effects of $\mathrm{LH}(500 \mathrm{mg} / \mathrm{kg})$ treatment on T1 among the SAL-SAL, SAL-LH, LH-SAL, and LH-LH groups for the conventional measure: OAE $\left(F_{3,48}=1.39, P>0.05\right)$, OAT $\left(F_{(3,48)}=1.44, P>0.05\right.$; Figure 1C,D), $\operatorname{EAE~}\left(F_{(3,48)}=2.20\right.$, $P>0.05)$, EAT $\left(F_{(3,48)}=1.49, P>0.05\right), C T\left(F_{3,48}=1.03\right.$,

Table 2. Conventional and ethological measures of mice after intraperitoneal administration of SAL or LH (200 mg/kg) before trial 1 and trial 2.

\begin{tabular}{|c|c|c|c|c|c|c|c|c|}
\hline \multirow[t]{2}{*}{ Behavior } & \multicolumn{2}{|c|}{ SAL-SAL $(N=10)$} & \multicolumn{2}{|c|}{ SAL-LH $(N=10)$} & \multicolumn{2}{|c|}{ LH-SAL $(N=10)$} & \multicolumn{2}{|c|}{ LH-LH $(\mathrm{N}=10)$} \\
\hline & Trial 1 & Trial 2 & Trial 1 & Trial 2 & Trial 1 & Trial 2 & Trial 1 & Trial 2 \\
\hline TE & $13.0 \pm 1.3$ & $12.0 \pm 0.7$ & $12.9 \pm 1.3$ & $10.1 \pm 1.1$ & $14.2 \pm 0.8$ & $11.2 \pm 1.2$ & $14.0 \pm 1.6$ & $14.7 \pm 1.3$ \\
\hline $\mathrm{EAE}$ & $9.0 \pm 0.8$ & $10.2 \pm 0.5$ & $9.0 \pm 0.5$ & $8.2 \pm 0.8$ & $9.8 \pm 0.8$ & $8.8 \pm 1.1$ & $9.2 \pm 1.0$ & $10.0 \pm 0.8$ \\
\hline EAT & $196.9 \pm 13.8$ & $260.3 \pm 2.9^{*}$ & $205.7 \pm 10.7$ & $259.8 \pm 7.67^{*}$ & $184.6 \pm 8.2$ & $212.6 \pm 15.8^{*}$ & $185.8 \pm 14.7$ & $221.9 \pm 13.6^{*}$ \\
\hline$\% \mathrm{OAE}$ & $29.7 \pm 3.0$ & $14.6 \pm 2.4^{*}$ & $26.2 \pm 5.3$ & $16.2 \pm 5.1$ & $28.9 \pm 5.1$ & $25.6 \pm 5.3$ & $32.7 \pm 5.8$ & $28.7 \pm 6.5$ \\
\hline$\% O A T$ & $13.5 \pm 3.3$ & $4.2 \pm 0.8^{*}$ & $13.9 \pm 4.2$ & $4.7 \pm 1.4^{*}$ & $14.6 \pm 3.4$ & $12.1 \pm 3.7$ & $17.1 \pm 4.0$ & $14.6 \pm 3.5$ \\
\hline CT & $66.5 \pm 11.4$ & $27.0 \pm 1.9^{*}$ & $52.4 \pm 5.5$ & $25.9 \pm 5.4^{*}$ & $71.4 \pm 4.3$ & $50.8 \pm 12.0$ & $62.6 \pm 8.7$ & $34.1 \pm 5.4^{*}$ \\
\hline Total SAP & $17.1 \pm 1.2$ & $13.8 \pm 1.2$ & $16.5 \pm 1.2$ & $14.0 \pm 1.1$ & $21.1 \pm 2.3$ & $20.0 \pm 3.1$ & $18.0 \pm 2.2$ & $15.5 \pm 1.9$ \\
\hline
\end{tabular}

Experimental protocol is given in Table 1. Data are reported as means \pm SEM. TE $=$ total entries; $E A E=$ enclosed-arm entries; EAT $=$ time in enclosed arms; \%OAE = percent of open-arm entries; \%OAT = percent of time in open arms; $\mathrm{CT}=$ center time; $\mathrm{SAP}=$ stretchedattend postures. ${ }^{*} \mathrm{P}<0.05$ for trial 1 compared to trial 2 (Kruskal-Wallis and Wilcoxon tests). 


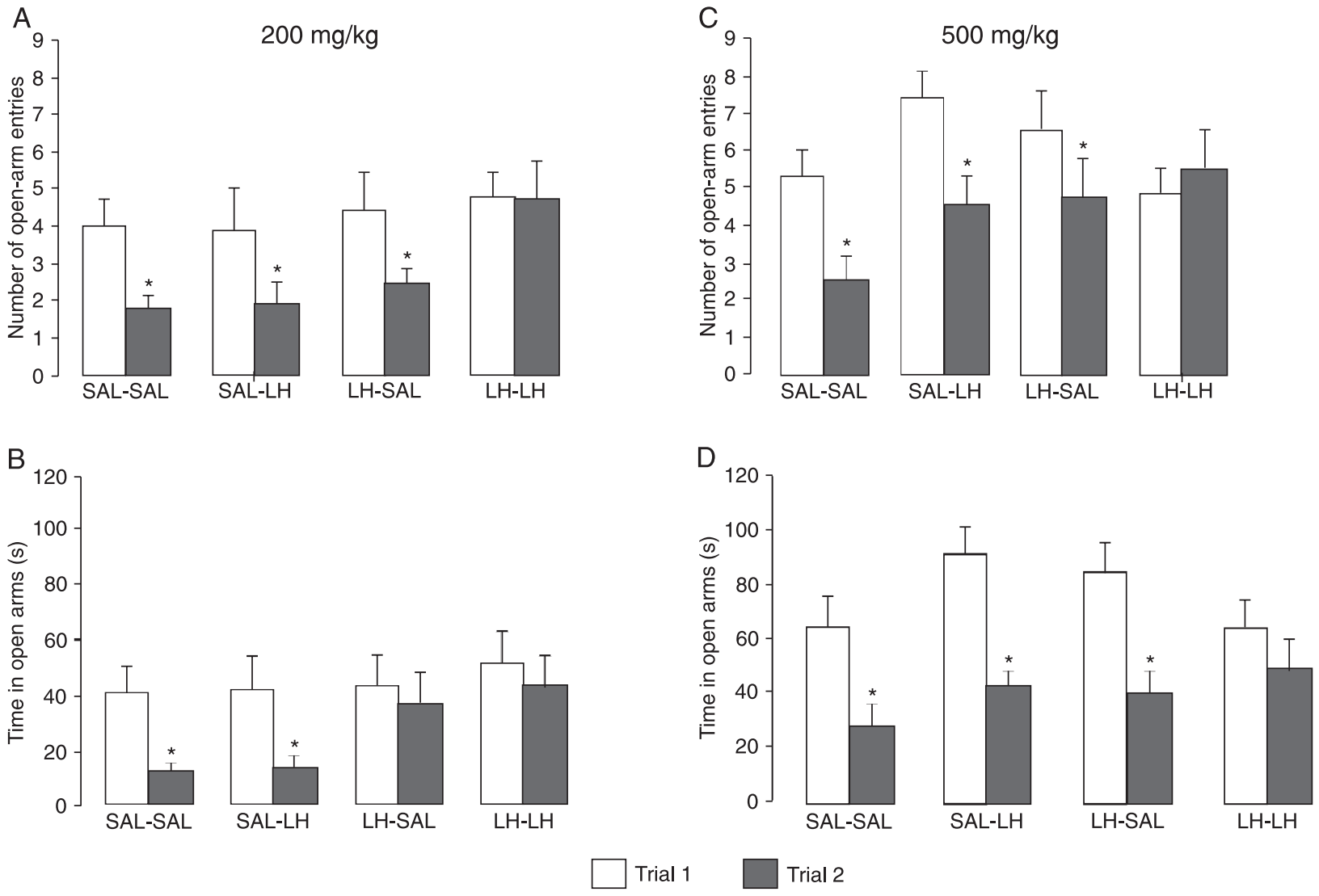

Figure 1. Effect of ip injection of SAL or L-histidine ( $\mathrm{LH})$ before trial 1 and trial 2 ( $24 \mathrm{~h}$ later) in the elevated plus-maze. $A$, Entries into the open arms after $200 \mathrm{mg} / \mathrm{kg} \mathrm{LH}$. B, Time spent in the open arms after $200 \mathrm{mg} / \mathrm{kg} \mathrm{LH}$. C, Entries into the open arms after $500 \mathrm{mg} / \mathrm{kg}$ LH. $D$, Time spent in the open arms after $500 \mathrm{mg} / \mathrm{kg} \mathrm{LH}$. Data are reported as means \pm SEM. Data in Pane/s $A$ and $B$ were analyzed by Kruskal-Wallis and Wilcoxon tests and those in Panels $C$ and $D$ were analyzed by ANOVA followed by the Fisher LSD test. ${ }^{*} P<$ 0.05 for trial 1 compared to trial 2 .

$P>0.05), \% O A E\left(F_{(3,48)}=0.68, P>0.05\right), \% O A T\left(F_{(3,48)}\right.$ $=0.26, \mathrm{P}>0.05 ;$ Table 3$)$, indicating that $\mathrm{LH}(500 \mathrm{mg} / \mathrm{kg})$ also has no action on anxiety.

During retest, at the dose of $500 \mathrm{mg} / \mathrm{kg} \mathrm{LH}$, ANOVA showed a significant reduction in OAE and OAT $\left(F_{(1,48)}\right.$ $=13.01,43.56$, respectively, $\mathrm{P}<0.05)$ for the SAL-SAL, SAL-LH, and LH-SAL groups. However, the Fisher LSD test revealed no significant changes in OAE or OAT for the LH-LH group (Figure 1C,D), indicating an inability to evoke memory for the LH-LH group $24 \mathrm{~h}$ later. ANOVA also indicated an alteration of \%OAE $\left(\mathrm{F}_{(1,48)}=8.83, \mathrm{P}<0.05\right)$ and $\%$ OAT $\left(F_{(1,48)}=43.57, P<0.05\right)$ in T2. The Fisher LSD test revealed that the LH-LH and LH-SAL groups did not reduce $\% O A E$ and only the LH-LH group did not reduce \%OAT. The experimental SAL-SAL, SAL-LH, and LH-SAL groups increased EAT $\left(F_{(1,48)}=41.17, \mathrm{P}<0.05\right)$ in T2 compared to T1. In addition, there were no significant effects on CT $\left(F_{(1,48)}=8.77, P>0.05\right.$; Table 3$)$.

With regard to the ethological measure (SAP), the Kruskal-Wallis test did not reveal significant effects of LH
(200 mg/kg) treatment on $\mathrm{T} 1$ among groups $(P=0.280)$ and this dose did not cause significant effects on SAP in T2 compared to $\mathrm{T} 1$ ( $P>0.05$, Wilcoxon test; see Table 2). At the dose of $500 \mathrm{mg} / \mathrm{kg} \mathrm{LH}$, ANOVA did not reveal effects on T1 between the experimental groups (SAP; $F_{(3,48)}=2.55$, $P>0.05)$. During retest, ANOVA showed an alteration in $\operatorname{SAP}\left(F_{(1,48)}=20.57, P<0.05\right)$. The post hoc test revealed a significantly decreased SAP for the SAL-SAL and SALLH groups, but not for the LH-SAL or LH-LH groups ( $P>$ 0.05 ; Table 3).

There were no significant changes in locomotor activity in T1 at the LH dose of $200 \mathrm{mg} / \mathrm{kg}$ represented by EAE $(P=$ 0.643 , Kruskal-Wallis test) and TE ( $P=0.09$, Kruskal-Wallis test) nor at a dose of $500 \mathrm{mg} / \mathrm{kg}\left(\mathrm{F}_{(3,48)}=2.20\right.$ and $2.01, P$ $>0.05$, respectively; Tables 2 and 3 ). For the highest dose, the $t$-test showed a decrease in EAE $\left[t_{44}=3.48, \mathrm{P}<0.05\right.$ ) and TE $\left(t_{44}=4.04, \mathrm{P}<0.05\right)$ for the LH group $(7.38 \pm 1.11$, $9.92 \pm 1.18$, respectively) compared to the SAL group (10.95 $\pm 0.89,16.45 \pm 1.10$, respectively). The Mann-Whitney U-test indicated an increase in immobility time $(P=0.019)$ for the 
Table 3. Conventional and ethological measures of mice after intraperitoneal administration of SAL or LH (500 mg/kg) before trial 1 and trial 2.

\begin{tabular}{|c|c|c|c|c|c|c|c|c|}
\hline \multirow[t]{2}{*}{ Behavior } & \multicolumn{2}{|c|}{ SAL-SAL $(N=11)$} & \multicolumn{2}{|c|}{ SAL-LH $(N=10)$} & \multicolumn{2}{|c|}{ LH-SAL $(\mathrm{N}=13)$} & \multicolumn{2}{|c|}{ LH-LH $(\mathrm{N}=15)$} \\
\hline & Trial 1 & Trial 2 & Trial 1 & Trial 2 & Trial 1 & Trial 2 & Trial 1 & Trial 2 \\
\hline TE & $12.7 \pm 1.0$ & $9.9 \pm 1.0$ & $16.5 \pm 0.9$ & $13.4 \pm 1.5$ & $15.2 \pm 1.7$ & $14.4 \pm 2.0$ & $14.6 \pm 1.2$ & $15.7 \pm 1.5$ \\
\hline EAE & $7.4 \pm 0.5$ & $7.3 \pm 0.7$ & $9.1 \pm 0.6$ & $8.9 \pm 0.9$ & $8.6 \pm 1.8$ & $9.7 \pm 1.3$ & $9.8 \pm 0.8$ & $10.2 \pm 0.9$ \\
\hline EAT & $185.6 \pm 13.9$ & $243.1 \pm 10.4^{*}$ & $154.1 \pm 10.6$ & $215.9 \pm 13.1^{*}$ & $170.0 \pm 1.9$ & $231.3 \pm 13.6^{*}$ & $181.5 \pm 11.3$ & $207.5 \pm 14.3$ \\
\hline$\% \mathrm{OAE}$ & $40.1 \pm 3.6$ & $25.5 \pm 6.0^{*}$ & $44.6 \pm 4.1$ & $32.3 \pm 3.6^{*}$ & $39.1 \pm 1.10$ & $31.8 \pm 4.3$ & $31.8 \pm 3.0$ & $33.5 \pm 4.9$ \\
\hline$\% O A T$ & $21.3 \pm 3.7$ & $9.2 \pm 2.4^{*}$ & $30.4 \pm 3.2$ & $13.9 \pm 2.1^{*}$ & $28.1 \pm 1.11$ & $13.2 \pm 2.5^{*}$ & $21.1 \pm 3.4$ & $16.3 \pm 2.8$ \\
\hline CT & $50.4 \pm 6.2$ & $29.1 \pm 4.5$ & $54.6 \pm 5.1$ & $42.2 \pm 8.0$ & $45.4 \pm 1.12$ & $28.9 \pm 7.3$ & $54.8 \pm 10.0$ & $43.4 \pm 8.5$ \\
\hline Total SAP & $18.6 \pm 1.5$ & $11.4 \pm 1.1^{*}$ & $14.4 \pm 1.0$ & $10.0 \pm 0.9^{*}$ & $19.9 \pm 1.13$ & $17.5 \pm 2.9$ & $17.0 \pm 2.4$ & $13.7 \pm 1.2$ \\
\hline
\end{tabular}

Experimental protocol is given in Table 1. Data are reported as means \pm SEM. TE $=$ total entries; $E A E=$ enclosed-arm entries; EAT $=$ time in enclosed arms; \%OAE = percent of open-arm entries; \%OAT = percent of time in open arms; $\mathrm{CT}=$ center time; SAP = stretchedattend postures. ${ }^{*} \mathrm{P}<0.05$ for trial 1 compared to trial 2 (ANOVA followed by the Fisher LSD test).

LH group $(8.88 \pm 4.17)$ compared to the SAL group $(2.56 \pm$ 1.81; data not shown). These results suggest an alteration in locomotor activity induced by $1000 \mathrm{mg} / \mathrm{kg} \mathrm{LH}$.

\section{Discussion}

The EPM test is used to evaluate the effects of drugs on anxiety. There is substantial evidence showing that drugs that increase open-arm activity are anxiolytic, while drugs that reduce the open-arm exploration are anxiogenic $(33,34)$. In the present study, L-histidine had no effects on anxiety at the dose of 200 and $500 \mathrm{mg} / \mathrm{kg}$, as shown by the lack of a significant difference in open-arm activity (open-arm time and open-arm entries) between the SAL-SAL and LH-LH groups in T1. Additionally, at the LH dose of $500 \mathrm{mg} / \mathrm{kg}$, no differences in open-arm or enclosed-arm activity or time spent in the central area occurred between groups during the first exposure. Data for the LH (1000 mg/kg) groups could not be interpreted in terms of anxiety due to a strong decrease in locomotor activity in T1.

Our results did not show an effect of $\mathrm{LH}$ on anxiety in mice submitted to the EPM. In contrast, Kumar et al. (24) detected an anxiogenic effect on mice, which received ip injections of LH before exposure to the EPM. In our view, these discrepancies could be related to some important differences in experimental conditions such as volume of injection and dimension and surface of the maze.

An interesting feature of the plus-maze is the fact that a single prior non-drugged experience of the maze significantly reduces open-arm activity in mice in a second trial (35). Thus, an increase in open-arm avoidance with repeated maze exposure has been observed in several studies $(36,37)$ and retest in the EPM is associated with behavioral changes indicative of aversive learning (38). We detected a significant decrease in frequency of open-arm entries and time spent in open arms for the SAL-SAL, SAL-
$\mathrm{LH}$ and $\mathrm{LH}-\mathrm{SAL}$ groups during the retest, indicating that learning occurred in T1 for these groups and that memory was retrieved in the second trial. The increase of open-arm avoidance behavior of rodents in T2 is thought to reflect the acquisition of spatial memory related to exploration of potentially dangerous areas of the maze (open arms) (29).

Considering that the LH-SAL group presented reduced open-arm entries and time spent in them in the second trial, acquisition and storage do not appear to be affected by $\mathrm{LH}$, as also observed for the SAL-SAL and SAL-LH groups. However, the LH-LH group did not reduce openarm activity during the retest, demonstrating that these mice did not remember the open arms as a dangerous area of the maze. Therefore, LH does appear to provoke a state-dependent memory retrieval deficit because the mice were unable to evoke emotional memory of the previous experience after $24 \mathrm{~h}$.

State-dependent memory can be defined in terms of a response, which can be acquired in a given (e.g., druginduced) state but may not be retrieved when the organism is in a different state (39). Zarrindast et al. (8) demonstrated that rats treated with $\mathrm{HA}$ both pre-training and pre-test (histamine-histamine) showed a significant increase in memory retrieval compared to the histamine-saline conditions. The authors suggest that HA induces state-dependent learning in interactions with opioid systems. The results obtained in the present study show that the mice treated with LH pre-T1 and pre-T2 did not demonstrate an increase in retrieval, but presented an impaired ability to evoke memory during the second trial in this state ( $\mathrm{LH}-\mathrm{LH})$, indicating a statedependent memory retrieval deficit. The present findings also suggest that this failure to evoke memory $24 \mathrm{~h}$ later produces an apparent state-dependent retrograde amnesia such as that similarly developed in the early course of Alzheimer's disease. Our results agree with other studies $(6,7)$ that suggest a probable relation between the neural 
histaminergic system and Alzheimer's disease.

Data previously reported by others $(17,18)$ have demonstrated the involvement of NHS in emotional memory processes in rodents. Our results are the first related to state-dependent memory retrieval, therefore differing from previous studies in which HA was administered during the memory consolidation period (post-test) (18) and the animals were not treated before testing, so that statedependency was not evaluated (17).

The most conspicuous observation in the analysis of the ethological measure was the absence of SAP reduction caused by L-histidine in mice previously exposed to the EPM. SAP has been interpreted as an index of risk assessment consisting of information-gathering behaviors displayed in potentially threatening situations (40). The LHLH groups did not reduce SAP, open-arm time or number of entries, therefore showing signs of memory deficit. Taken together, these results confirm that, while HA did not act on anxiety, it appeared to impair memory retrieval in a statedependent manner in the EPM.

There were no alterations in general locomotor activity (number of entries in the enclosed arms and total number of entries) during retest at the LH dose of 200 and $500 \mathrm{mg} /$ $\mathrm{kg}$. Therefore, there was no possibility of habituation to the

\section{References}

1. Hass $\mathrm{H}$, Panula $\mathrm{P}$. The role of histamine and the tuberomammilary nucleus in the nervous system. Neuroscience 2003; 4: $121-130$.

2. Leurs $\mathrm{R}$, Smit MJ, Timmerman H. Molecular pharmacological aspects of histamine receptors. Pharmacol Ther 1995; 66: 413-463.

3. Faganello FR, Mattioli R. Anxiolytic-like effect of chlorpheniramine in inhibitory avoidance in goldfish submitted to telencephalic ablation. Prog Neuropsychopharmacol Biol Psychiatry 2007; 31: 269-274.

4. Faganello FR, Mattioli R. Chlorpheniramine facilitates inhibitory avoidance in teleosts submitted to telencephalic ablation. Braz J Med Biol Res 2008; 41: 398-402.

5. Meguro K, Yanai K, Sakai N, Sakurai E, Maeyama K, Sasaki $\mathrm{H}$, et al. Effects of thioperamide, a histamine H3 antagonist, on the step-through passive avoidance response and histidine decarboxylase activity in senescence-accelerated mice. Pharmacol Biochem Behav 1995; 50: 321-325.

6. Ishunina TA, van Heerikhuize JJ, Ravid R, Swaab DF. Estrogen receptors and metabolic activity in the human tuberomamillary nucleus: changes in relation to sex, aging and Alzheimer's disease. Brain Res 2003; 988: 84-96.

7. Yanai K, Tashiro M. The physiological and pathophysiological roles of neuronal histamine: an insight from human positron emission tomography studies. Pharmacol Ther 2007; 113: 1-15.

8. Zarrindast MR, Khalilzadeh A, Malekmohammadi N, FazliTabaei S. Influence of morphine- or apomorphine-induced sensitization on histamine state-dependent learning in the step-down passive avoidance test. Behav Brain Res 2006; same drug treatment on both days, especially for the LHLH group, since there were no differences in the number of entries in the enclosed arms. The highest dose of LH (1000 $\mathrm{mg} / \mathrm{kg}$ ) provoked a decrease in locomotor activity for the LH group in T1, thus preventing conclusive analyses of the effects of this LH dose on anxiety and memory.

The EPM, especially in the second trial of this test, demonstrated its value as a possible tool to evaluate memory impairment, since there was a delay between learning (T1) and retrieval (T2). Thus, the results of the present study are an important first step in establishing a valid animal model to understand memory impairments.

The results of the present study suggest that LH does not have an effect on anxiety and produces a state-dependent memory retrieval deficit during retest of mice in the EPM. Furthermore, the EPM test can also be used as a model that induces state-dependent memory retrieval deficit, although further investigation is required.

\section{Acknowledgments}

Research supported by CAPES, CNPq (\#300312/20075 and \#471242/2007-1), and FAPESP (\#07/03822-0).

\section{1: $50-55$}

9. Da Silva WC, Bonini JS, Bevilaqua LR, Izquierdo I, Cammarota $\mathrm{M}$. Histamine enhances inhibitory avoidance memory consolidation through a $\mathrm{H} 2$ receptor-dependent mechanism. Neurobiol Learn Mem 2006; 86: 100-106.

10. Huston JP, Wagner $U$, Hasenohrl RU. The tuberomammillary nucleus projections in the control of learning, memory and reinforcement processes: evidence for an inhibitory role. Behav Brain Res 1997; 83: 97-105.

11. Spieler RE, Nelson CA, Huston JP, Mattioli R. Post-trial administration of $\mathrm{H} 1$ histamine receptor blocker improves appetitive reversal learning and memory in goldfish, Carassius auratus. Neurosci Lett 1999; 277: 5-8.

12. Coelho JL, Medalha CC, Mattioli R. Analysis of the effects of CPA and L-histidine on goldfish tested on a conditioned place preference model. Behav Brain Res 2001; 124: 161165.

13. Prast $H$, Argyriou A, Philippu A. Histaminergic neurons facilitate social memory in rats. Brain Res 1996; 734: 316-318.

14. Peitsaro N, Kaslin J, Anichtchik OV, Panula P. Modulation of the histaminergic system and behaviour by alphafluoromethylhistidine in zebrafish. J Neurochem 2003; 86: 432-441.

15. Ito $\mathrm{C}$, Shen $\mathrm{H}$, Toyota $\mathrm{H}$, Kubota $\mathrm{Y}$, Sakurai $\mathrm{E}$, Watanabe $\mathrm{T}$, et al. Effects of the acute and chronic restraint stresses on the central histaminergic neuron system of Fischer rat. Neurosci Lett 1999; 262: 143-145.

16. Malmberg-Aiello P, Ipponi A, Bartolini A, Schunack W. Mouse light/dark box test reveals anxiogenic-like effects by activation of histamine $\mathrm{H} 1$ receptors. Pharmacol Biochem Behav 
2002; 71: 313-318.

17. Kamei C, Tasaka K. Effect of histamine on memory retrieval in old rats. Biol Pharm Bull 1993; 16: 128-132.

18. de Almeida MA, Izquierdo I. Memory facilitation by histamine. Arch Int Pharmacodyn Ther 1986; 283: 193-198.

19. Alvarez EO, Ruarte MB. Histaminergic neurons of the ventral hippocampus and the baso-lateral amygdala of the rat: functional interaction on memory and learning mechanisms. Behav Brain Res 2002; 128: 81-90.

20. Frisch C, Hasenohrl RU, Huston JP. The histamine H1antagonist chlorpheniramine facilitates learning in aged rats. Neurosci Lett 1997; 229: 89-92.

21. File SE, Zangrossi H Jr, Viana M, Graeff FG. Trial 2 in the elevated plus-maze: a different form of fear? Psychopharmacology 1993; 111: 491-494.

22. Pellow S, Chopin P, File SE, Briley M. Validation of open:closed arm entries in an elevated plus-maze as a measure of anxiety in the rat. $J$ Neurosci Methods 1985; 14 : 149-167.

23. Carobrez AP, Bertoglio LJ. Ethological and temporal analyses of anxiety-like behavior: the elevated plus-maze model 20 years on. Neurosci Biobehav Rev 2005; 29: 1193-1205.

24. Kumar KV, Krishna DR, Palit G. Histaminergic $\mathrm{H} 1$ receptors mediate L-histidine-induced anxiety in elevated plus-maze test in mice. Behav Pharmacol 2007; 18: 213-217.

25. Lister RG. The use of a plus-maze to measure anxiety in the mouse. Psycopharmacol 1987; 92: 180-185.

26. Garcia AM, Cardenas FP, Morato S. Effect of different illumination levels on rat behavior in the elevated plus-maze. Physiol Behav 2005; 85: 265-270.

27. Rodgers RJ, Johnson NJ. Factor analysis of spatiotemporal and ethological measures in the murine elevated plus-maze test of anxiety. Pharmacol Biochem Behav 1995; 52: 297 303.

28. Dal-Col ML, Pereira LO, Rosa VP, Calixto AV, Carobrez AP, Faria MS. Lack of midazolam-induced anxiolysis in the plusmaze Trial 2 is dependent on the length of Trial 1. Pharmacol Biochem Behav 2003; 74: 395-400.

29. Bertoglio LJ, Joca SR, Guimaraes FS. Further evidence that anxiety and memory are regionally dissociated within the hippocampus. Behav Brain Res 2006; 175: 183-188.
30. Bertoglio LJ, Carobrez AP. Behavioral profile of rats submitted to session 1-session 2 in the elevated plus-maze during diurnal/nocturnal phases and under different illumination conditions. Behav Brain Res 2002; 132: 135-143.

31. Cruz AP, Frei F, Graeff FG. Ethopharmacological analysis of rat behavior on the elevated plus-maze. Pharmacol Biochem Behav 1994; 49: 171-176.

32. Cole JC, Rodgers RJ. An ethological analysis of the effects of chlordiazepoxide and bretazenil (Ro 16-6028) in the murine elevated plus-maze. Behav Pharmacol 1993; 4: 573580.

33. Brandao ML, Cardoso SH, Melo LL, Motta V, Coimbra NC. Neural substrate of defensive behavior in the midbrain tectum. Neurosci Biobehav Rev 1994; 18: 339-346.

34. Mendes-Gomes J, Nunes-de-Souza RL. Concurrent nociceptive stimulation impairs the anxiolytic effect of midazolam injected into the periaqueductal gray in mice. Brain Res 2005; 1047: 97-104.

35. Fernandes C, File SE. The influence of open arm ledges and maze experience in the elevated plus-maze. Pharmacol Biochem Behav 1996; 54: 31-40.

36. Canto-de-Souza A, Luiz Nunes-de-Souza R, Rodgers RJ. Anxiolytic-like effect of way-100635 microinfusions into the median (but not dorsal) raphe nucleus in mice exposed to the plus-maze: influence of prior test experience. Brain Res 2002; 928: 50-59.

37. De Souza MM, Schenberg LC, de Padua CA. NMDAcoupled periaqueductal gray glycine receptors modulate anxioselective drug effects on plus-maze performance. Behav Brain Res 1998; 90: 157-165.

38. File SE, Mabbutt PS, Hitchcott PK. Characterisation of the phenomenon of "one-trial tolerance" to the anxiolytic effect of chlordiazepoxide in the elevated plus-maze. Psychopharmacology 1990; 102: 98-101.

39. Colpaert FC, Koek W, Bruins Slot LA. Evidence that mnesic states govern normal and disordered memory. Behav Pharmacol 2001; 12: 575-589.

40. Blanchard RJ, Yudko EB, Rodgers RJ, Blanchard DC. Defense system psychopharmacology: an ethological approach to the pharmacology of fear and anxiety. Behav Brain Res 1993; 58: 155-165. 